\title{
Important Sensory Properties Differentiating Premium Rice Varieties
}

\author{
Elaine T. Champagne $\cdot$ Karen L. Bett-Garber • Melissa A. Fitzgerald • \\ Casey C. Grimm • Jeanne Lea $\cdot$ Ken'ichi Ohtsubo • Supanee Jongdee $•$ Lihong Xie • \\ Priscila Zaczuk Bassinello • Adoracion Resurreccion • Rauf Ahmad • \\ Fatemah Habibi • Russell Reinke
}

Received: 21 May 2010/Accepted: 1 November 2010/Published online: 4 December 2010

(C) US Government 2010

\begin{abstract}
In rice-consuming countries, specific varieties are recognized as premium, "gold standard" varieties, while others are recognized as being superior but second best, despite being identical using the current suite of tools to evaluate quality. The objectives of this study were to determine if there are distinguishable differences in sensory properties of premium and second best varieties and whether these differences are common to premium varieties. Color, an important sensory property, was determined on the raw and cooked rice using a colorimeter. As raw rice, some of the premium varieties were whiter than their second best counterparts while others were not. However, when cooked, with two exceptions, the premium varieties were of the same or greater whiteness than their counterparts. A trained sensory panel employed descriptive sensory analysis, an objective tool, to characterize and analytically
\end{abstract}

E. T. Champagne $(\bowtie) \cdot$ K. L. Bett-Garber $\cdot$ C. C. Grimm $\cdot$ J. Lea USDA ARS Southern Regional Research Center,

P.O. Box 19687, New Orleans, LA 70179, USA

e-mail: elaine.champagne@ars.usda.gov

M. A. Fitzgerald · A. Resurreccion

Grain Quality, Nutrition and Postharvest Center,

International Rice Research Institute,

Metro Manila, Philippines

K. Ohtsubo

Niigata University,

Niigata, Japan

S. Jongdee

Ubon Ratchathani Rice Research Center,

Ubon Ratchathani, Thailand

\section{Xie}

China National Rice Research Institute,

Hangzhou, China measure the flavor (aromatics, taste, mouthfeel) and texture of premium and second best varieties collected from nine rice-consuming countries. Sweet taste, popcorn aroma/ flavor, and water-like metallic mouthfeel showed significant differences in intensity between the premium-second best variety pairs. Slickness, roughness, and springiness were the major traits that distinguished the texture of varieties. Quality evaluation programs do not routinely measure these texture and flavor traits, but the fact that they distinguished the varieties in most pairs indicates that their measurement should be added to the suite of grain quality tests in the development of new higher-yielding, stresstolerant varieties. The incorporation of premium quality will ensure that quality is no impediment to widespread adoption leading to enhanced productivity and food security.

\section{P. Z. Bassinello}

EMBRAPA Rice and Beans,

Santo Antonio de Goias,

Goias, Brazil

R. Ahmad

National Agricultural Research Centre, Islamabad, Pakistan

F. Habibi

Rice Research Institute of Iran,

Rasht, Iran

R. Reinke

Industry and Investment NSW, EH Graham Centre for Agricultural Innovation and Yanco Agricultural Institute, Yanco, Australia 
Keywords Rice flavor . Rice texture $\cdot$ Rice color $\cdot$ Rice quality $\cdot$ Descriptive sensory analysis $\cdot$ Amylose $\cdot$ Protein

\section{Introduction}

Rice consumers, particularly from countries for which rice is the staple, have strong preferences for the sensory properties of rice. Different countries have different requirements for quality, and within countries, a range of preferences can be found.

Many of the varieties famed for their quality were selected/released many decades ago (Fitzgerald et al. 2009). In the ensuing years, rice improvement programs have significantly increased attainable yield and yield potential, but high yield has not, in many cases, been successfully combined with the high quality of the older varieties. Internationally famous examples, due to export and in part to the effects of migration on national cuisines, are the Japanese variety Koshihikari, the Thai fragrant variety Khao Dawk Mali 105, Super Basmati which is grown in the Punjab between Pakistan and India, and IR64 which is grown in many countries. However, all rice-consuming regions have their favorite varieties, and in most cases, these too have persisted for several decades.

Every rice improvement program strives to replace lower-yielding, high-quality varieties with higher-yielding versions of them. To date, rice breeders have generally failed to combine high yields with optimal quality because not all quality traits are defined (Fitzgerald et al. 2009). Quality evaluation programs have been measuring the same traits for many decades, and current tools of evaluating grain quality cannot distinguish an old variety from a potential replacement, though consumers are readily able to do so. Rapid adoption, resulting from fortuitous combination rather than planned breeding, occurs when the quality of the grain is reproduced in the new variety. An example is IR64, which was released in the 1980s. IR64 is still, 30 years later, grown on over a million hectares of land each year. The challenge that rice improvement programs face is that consumers cannot elaborate on what is considered to be good quality, so it is difficult to identify new and relevant traits.

Descriptive sensory analysis is an objective tool used to characterize and analytically measure traits of aroma, flavor, and texture of foods by a trained panel (Meilgaard et al. 2007). The technique has been used extensively for determining the effect of different growing and/or processing conditions on sensory properties of rice (Champagne et al. 1997, 2004a, b, 2007, 2009; Meullenet et al. 1999, 2000).

Using premium and second best varieties sourced from the national programs of nine rice-growing countries around the world, the first objective of this study was to determine if there are distinguishable differences in the sensory properties of premium varieties, compared with one from the same country with identical grain quality, as defined by our current suite of tools, but which does not reach the superior classification. The second objective was to determine whether identified differences are common to premium varieties. The third objective was to identify the most important descriptors of sensory quality that distinguished each premium and second best pair and to determine if there was any correlation with traits of quality that are currently measured. Premium and second best varieties were determined by each national rice institute using data on crop growth, persistence of premium varieties, adoption rates of second best varieties, and market prices of each of the premium and second best varieties.

\section{Results and discussion}

Premium and second best varieties were obtained from nine countries. The two varieties in each pair were very similar based on the current suite of quality evaluation tools. Table 1 shows the variety, the country of origin, gelatinization temperature, amylose content, and protein content. Only the pair from Pakistan differed in gelatinization temperature, which was unexpected since the standard for Basmati quality defines intermediate gelatinization temperature. Perhaps, some environmental condition during grain-filling led to the low value obtained for Basmati 385. For most pairs, there were small differences in amylose content, but in most cases, these differences did not cross the current classifications of amylose (Fitzgerald et al. 2009). Protein content ranged from $5.9 \%$ to $11.2 \%$ across the set, but in most cases, the protein content was similar for the pairs although statistical analysis of technical replicates indicates significant differences between many pairs

\section{Color}

One of the most important attributes of raw and cooked rice is degree of whiteness (Goodwin et al. 1992, Suwansri et al. 2002). The whiteness $\left(L^{*}\right)$ of the raw premium rice compared to its second best counterpart was not an indicator of the relative whiteness of the cooked rice (Tables 2 and 3). However, when cooked, the only premium rice varieties that were not of the same or greater whiteness than their second best counterparts were IR64 and BR IRGA 417 (2009).

Green-red color $\left(a^{*}\right)$ varied markedly across countries and between premium-second best variety pairs (Table 3 ). Cooking decreased the green color of all the varieties and resulted in $a^{*}$ values that differed by no more than 0.1 unit. 
Table 1 Premium (rank 1) and second best (rank 2) variety pairs with country of origin (GT) type $>74^{\circ} \mathrm{C}$; intermediate GT type $70-74^{\circ} \mathrm{C}$; low $\mathrm{GT}<70^{\circ} \mathrm{C}$

${ }^{\mathrm{b}}$ Values with different letters are significantly $(P<0.05)$ different between premium and second best varieties

\begin{tabular}{|c|c|c|c|c|c|}
\hline Country & Variety & Rank & $\mathrm{GT}^{\circ} \mathrm{C}^{\mathrm{a}}$ & Apparent amylose ${ }^{\mathrm{b}}$ & Protein $^{\mathrm{b}}$ \\
\hline \multirow[t]{2}{*}{ Thailand } & KDML105 & 1 & 66 & $15.7 \mathrm{a}$ & $6.9 \mathrm{a}$ \\
\hline & PTT1 & 2 & 65 & $16.6 \mathrm{~b}$ & $8.0 \mathrm{~b}$ \\
\hline \multirow[t]{2}{*}{ China } & Zhongzheyou 1 & 1 & 76 & $15.5 \mathrm{a}$ & $7.2 \mathrm{a}$ \\
\hline & Guodao 6 & 2 & 76 & $18.5 b$ & $7.4 \mathrm{~b}$ \\
\hline \multirow[t]{2}{*}{ Philippines } & IR64 & 1 & 77 & $21.7 \mathrm{a}$ & $8.2 \mathrm{a}$ \\
\hline & IRRI-132 & 2 & 78 & $17.0 \mathrm{~b}$ & $8.7 b$ \\
\hline \multirow[t]{2}{*}{ Japan } & Koshihikari & 1 & 67 & $18.1 \mathrm{a}$ & $5.9 \mathrm{a}$ \\
\hline & Koshiibuki & 2 & 69 & $16.1 \mathrm{~b}$ & $5.9 \mathrm{a}$ \\
\hline \multirow[t]{2}{*}{ Australia } & Pelde & 1 & 74 & $21.2 \mathrm{a}$ & $7.0 \mathrm{a}$ \\
\hline & Langi & 2 & 74 & $21.4 \mathrm{a}$ & $7.4 \mathrm{~b}$ \\
\hline \multirow[t]{2}{*}{ Pakistan } & Super Basmati & 1 & 73 & $23.4 \mathrm{a}$ & $8.0 \mathrm{a}$ \\
\hline & Basmati 385 & 2 & 67 & $24.9 \mathrm{~b}$ & $8.2 b$ \\
\hline \multirow[t]{2}{*}{ India } & Samba Mahsuri & 1 & 75 & $24.0 \mathrm{a}$ & $10.4 \mathrm{a}$ \\
\hline & Swarna & 2 & 75 & $24.2 \mathrm{a}$ & $8.6 b$ \\
\hline \multirow[t]{2}{*}{ Iran } & Hashemi & 1 & 76 & $21.3 \mathrm{a}$ & $10.3 \mathrm{a}$ \\
\hline & Khazar & 2 & 75 & $22.2 \mathrm{a}$ & $9.2 b$ \\
\hline \multirow[t]{2}{*}{ Brazil } & BR IRGA-417 (2008) & 1 & 62 & $24.9 \mathrm{a}$ & $8.7 \mathrm{a}$ \\
\hline & BRS Jaçanã (2008) & 2 & 62 & $24.6 \mathrm{a}$ & $7.7 b$ \\
\hline \multirow[t]{2}{*}{ Brazil } & BR IRGA-417 (2009) & 1 & Low & $25.5 \mathrm{a}$ & $7.5 \mathrm{a}$ \\
\hline & BRS Primavera (2009) & 2 & Intermediate & $23.5 b$ & $11.2 \mathrm{~b}$ \\
\hline
\end{tabular}

Table 2 Rice samples prepared using rice cooker and excess water methods

\begin{tabular}{|c|c|c|c|c|}
\hline \multirow[b]{2}{*}{ Variety } & \multicolumn{4}{|c|}{ Rice cooker methods } \\
\hline & Wash (no. of times) & Water-rice ratio $(w: w)$ & Soak time (min) & Mean cook time (min) to cooker shut-off \\
\hline KDML105 & 2 & $1.5: 1.0$ & 0 & 20 \\
\hline PTT1 & 2 & $1.5: 1.0$ & 0 & 21 \\
\hline Zhongzheyou 1 & 3 & $1.35: 1.0$ & 15 & 18 \\
\hline Guodao 6 & 3 & $1.5: 1.0$ & 15 & 19 \\
\hline IR64 & 3 & $1.4: 1.0$ & 10 & 20 \\
\hline IRRI-132 ${ }^{\mathrm{a}}$ & 3 & 1.4:1.0 & 10 & 20 \\
\hline Koshihikari & 2 & $1.4: 1.0$ & 30 & 18 \\
\hline Koshiibuki & 2 & $1.4: 1.0$ & 30 & 19 \\
\hline Langi & 2 & $1.4: 1.0$ & 0 & 22 \\
\hline \multirow[t]{2}{*}{ Pelde } & 2 & $1.4: 1.0$ & 0 & 22 \\
\hline & \multicolumn{4}{|c|}{ Pan Methods } \\
\hline Variety & Wash (no. of times) & Water-rice ratio $(v: v)$ & Soak time (min) & Mean cook time \\
\hline Super Basmati & 3 & Excess & 30 & 17 \\
\hline Basmati 385 & 3 & Excess & 30 & 20 \\
\hline Samba Mahsuri & 3 & Excess & 30 & 21 \\
\hline Swarna & 3 & Excess & 30 & 21 \\
\hline Hashemi $^{\mathrm{b}}$ & 5 & Excess & 120 & 11 \\
\hline Khazar $^{\mathrm{b}}$ & 5 & Excess & 120 & 10 \\
\hline BR IRGA-417 (2008) & 3 & Complete evaporation $(2: 1)$ & 0 & 16 \\
\hline BR IRGA-417 (2009) & 3 & Complete evaporation $(2: 1)$ & 0 & 15 \\
\hline BRS Jaçanã & 3 & Complete evaporation $(2: 1)$ & 0 & 17 \\
\hline BRS Primavera & 3 & Complete evaporation $(2: 1)$ & 0 & 15 \\
\hline
\end{tabular}

${ }^{\text {a }}$ Drained in strainer $15 \mathrm{~min}$ after washing

${ }^{\mathrm{b}}$ Rice samples were steamed on top of hot oil for 10 min following cooking 
Table 3 Tristimulus $L^{*}, a^{*}$, and $b^{*}$ values for color measured using a HunterLab MiniScan XE Plus Diffuse LAV M072096 colorimeter

$L^{*}$ is the measure of brightness from black (0) to white (100); $a^{*}$ describes red-green color with positive $a^{*}$ values redness and negative $a^{*}$ values greenness; $b^{*}$ describes yellow-blue color with positive $b^{*}$ values yellowness and negative $b^{*}$ values blueness. Values with different letters are significantly $(P<0.05)$ different between premium and second best variety pairs

\begin{tabular}{|c|c|c|c|c|c|c|}
\hline \multirow[t]{2}{*}{ Variety } & \multicolumn{3}{|l|}{ Raw } & \multicolumn{3}{|c|}{ Cooked } \\
\hline & $L^{*}$ & $a^{*}$ & $b^{*}$ & $L^{*}$ & $a^{*}$ & $b^{*}$ \\
\hline Zhongzheyou & $79.6 \mathrm{a}$ & $-0.58 \mathrm{a}$ & $11.1 \mathrm{a}$ & $77.1 \mathrm{a}$ & $-1.8 \mathrm{a}$ & $6.0 \mathrm{a}$ \\
\hline Guodao 6 & $75.8 \mathrm{~b}$ & $-0.50 \mathrm{a}$ & $11.3 \mathrm{a}$ & $76.7 \mathrm{a}$ & $-1.9 \mathrm{~b}$ & $5.6 \mathrm{a}$ \\
\hline Koshihikari & $77.1 \mathrm{a}$ & $-0.83 a$ & $12.8 \mathrm{a}$ & $75.9 \mathrm{a}$ & $-2.1 \mathrm{a}$ & $5.1 \mathrm{a}$ \\
\hline Koshiibuki & $74.7 b$ & $-0.98 b$ & $12.9 \mathrm{a}$ & $75.6 \mathrm{a}$ & $-2.1 \mathrm{a}$ & $5.0 \mathrm{a}$ \\
\hline IR 64 & $78.1 \mathrm{a}$ & $-0.62 \mathrm{a}$ & $12.3 \mathrm{a}$ & $77.3 \mathrm{a}$ & $-1.8 \mathrm{a}$ & $5.2 \mathrm{a}$ \\
\hline IRRI 1132 & $79.1 \mathrm{~b}$ & $0.20 \mathrm{~b}$ & $13.8 \mathrm{~b}$ & $79.3 b$ & $-1.7 \mathrm{a}$ & $7.0 \mathrm{~b}$ \\
\hline KDML105 & $77.3 \mathrm{a}$ & $-0.95 \mathrm{a}$ & $11.6 \mathrm{a}$ & $79.0 \mathrm{a}$ & $-2.0 \mathrm{a}$ & $5.0 \mathrm{a}$ \\
\hline PTT1 & $71.9 \mathrm{~b}$ & $0.03 b$ & $13.4 \mathrm{~b}$ & $78.0 \mathrm{~b}$ & $-1.9 b$ & $5.2 \mathrm{a}$ \\
\hline Pelde & $75.8 \mathrm{a}$ & $-0.57 \mathrm{a}$ & $13.5 \mathrm{a}$ & $77.7 \mathrm{a}$ & $-2.0 \mathrm{a}$ & $5.8 \mathrm{a}$ \\
\hline Langi & $77.1 \mathrm{~b}$ & $-0.77 \mathrm{~b}$ & $12.5 b$ & $77.9 \mathrm{a}$ & $-2.1 \mathrm{a}$ & $6.0 \mathrm{a}$ \\
\hline IRGA 417 (2008) & $76.0 \mathrm{a}$ & $-1.02 \mathrm{a}$ & $10.0 \mathrm{a}$ & $76.8 \mathrm{a}$ & $-1.8 \mathrm{a}$ & $2.4 \mathrm{a}$ \\
\hline Jaçanã & $75.4 b$ & $-0.49 \mathrm{~b}$ & $11.5 b$ & $76.7 \mathrm{a}$ & $-1.9 b$ & $3.2 \mathrm{~b}$ \\
\hline IRGA 417 (2009) & $73.3 \mathrm{a}$ & $-0.48 \mathrm{a}$ & $11.7 \mathrm{a}$ & $76.4 \mathrm{a}$ & $-1.7 \mathrm{a}$ & $3.3 \mathrm{a}$ \\
\hline Primavera & $73.2 \mathrm{a}$ & $-0.95 b$ & $12.5 b$ & $78.9 b$ & $-1.8 b$ & $4.8 \mathrm{~b}$ \\
\hline Super Basmati & $77.1 \mathrm{a}$ & $-0.33 a$ & $12.9 \mathrm{a}$ & $78.1 \mathrm{a}$ & $-1.8 \mathrm{a}$ & $3.9 \mathrm{a}$ \\
\hline Basmati 385 & $76.8 \mathrm{~b}$ & $0.96 \mathrm{~b}$ & $15.3 b$ & $76.2 b$ & $-1.8 b$ & $2.7 \mathrm{~b}$ \\
\hline Sambha Mahsuri & $76.3 \mathrm{a}$ & $0.21 \mathrm{a}$ & $15.3 \mathrm{a}$ & $78.6 \mathrm{a}$ & $-1.7 \mathrm{a}$ & $4.8 \mathrm{a}$ \\
\hline Swarna & $78.6 b$ & $-0.40 \mathrm{~b}$ & $13.6 b$ & $76.9 b$ & $-1.7 \mathrm{a}$ & $3.4 \mathrm{~b}$ \\
\hline Hashemi & $77.7 \mathrm{a}$ & $0.12 \mathrm{a}$ & $15.3 \mathrm{a}$ & $79.1 \mathrm{a}$ & $-1.8 \mathrm{a}$ & $5.4 \mathrm{a}$ \\
\hline Khazar & $78.1 \mathrm{~b}$ & $0.12 \mathrm{a}$ & $15.0 \mathrm{~b}$ & $79.1 \mathrm{a}$ & $-1.8 \mathrm{a}$ & $5.0 \mathrm{~b}$ \\
\hline
\end{tabular}

In the raw rice, yellow color $\left(b^{*}\right)$ was significantly lower in the premium varieties IR64, KDML-105, BR IRGA-417 (2008 and 2009), and Super Basmati when compared to their second best counterparts. The converse relationship was observed for the Pelde-Langi, Sambha Mahsuri-Swarna, and Hashemi-Khazar pairs. No significant differences in $b^{*}$ were observed for the pairs from Japan (KoshihikariKoshiibuki) or China (Zhongzheyou 1-Guodao 6). Upon cooking, varieties became less yellow $\left(b^{*}=2.4-7.0\right.$ versus $10.0-15.3)$ and the significant differences in $b^{*}$ observed for the raw varieties were still seen for most variety pairs. No parameter of color provided a consistent explanation of differences in quality.

Comparison of flavor of premium and second best varieties

No significant $(P<0.1)$ flavor (aromatics, taste, mouthfeel) differences were observed between the premium and second best variety pairs from Japan, India, and one set from Brazil. The other second best variety from Brazil, BRS Jaçanã, only differed from BR IRGA-417 (also harvested in 2008) by having a lower level of sour/silage (Table 4). Sour/silage is an off-flavor note that increases with increase in harvest moisture content of paddy and length of storage prior to drying (Champagne et al. 2004a) and, thus, was not inherently higher in BR IRGA-417.
The flavor of the other premium-second best variety pairs differed in intensity for only a few attributes, as shown in Table 4. The premium varieties from China and the Philippines were distinguished from their second best counterparts by having significantly higher levels of sweet taste (desirable attribute) and lower level of water-like metallic (undesirable attribute). A lower level of water-like metallic also distinguished the premium Super Basmati from Pakistan from its second best counterpart Basmati 385. Water-like metallic has been shown to decrease with storage time of rough rice (Meullenet et al. 2000), so the difference in intensities between the Super Basmati and the longer-stored Basmati-385 can be attributed to differences between varieties and not storage duration. The intensity of water-like metallic was also numerically but not significantly lower in the premium varieties KDML105, Pelde, IRGA-417 (2008), and Sambha Mahsuri compared to their second best counterparts. A comparison of the combined premium varieties with the combined second best varieties showed water-like metallic to be significantly lower $(P=$ 0.02 ) in the premium varieties. No other flavor attribute was significantly different between combined premium and second best varieties.

The compound 2-acetyl-1-pyrroline (2-AP) imparts a popcorn flavor to fragrant rice varieties (Buttery et al. 1983; Schieberle 1991). Premium KDML105 was significantly 
Table 4 Flavor attributes that differed significantly $(P<0.1)$ in intensity between premium and second best variety pairs

\begin{tabular}{|c|c|c|c|c|}
\hline Flavor attribute & Country & Premium variety & Second best variety & Significant $P$ \\
\hline & China & Zhongzheyou 1 & Guodao6 & \\
\hline Dairy & & 0.8 & 0.7 & 0.04 \\
\hline Water-like metallic & & 0.5 & 0.7 & 0.10 \\
\hline \multirow[t]{2}{*}{ Sweet taste } & & 1.3 & 1.0 & 0.07 \\
\hline & Philippines & IR64 & IRRI-132 & \\
\hline Corn & & 0.6 & 0.2 & 0.01 \\
\hline Sweet aromatic & & 0.6 & 0.2 & 0.03 \\
\hline Water-like Metallic & & 0.7 & 1.3 & 0.10 \\
\hline Sweet taste & & 1.1 & 0.5 & $<0.01$ \\
\hline \multirow[t]{2}{*}{ Astringent } & & 1.1 & 1.5 & 0.02 \\
\hline & Thailand & KDML105 & PTT1 & \\
\hline \multirow[t]{2}{*}{ Popcorn } & & 1.5 & 1.1 & 0.08 \\
\hline & Australia & Pelde & Langi & \\
\hline Sewer/animal & & 0.2 & 0.7 & 0.09 \\
\hline Grain/starchy & & 1.8 & 2.2 & 0.02 \\
\hline Sweet aromatic & & 0.3 & 0.6 & 0.07 \\
\hline \multirow[t]{2}{*}{ Sweet taste } & & 1.0 & 1.4 & 0.04 \\
\hline & Brazil & BR IRGA-417 (2008) & Jaçanã (2008) & \\
\hline \multirow[t]{2}{*}{ Sour/silage } & & 1.2 & 0.6 & 0.06 \\
\hline & Pakistan & Super Basmati & Basmati 385 & \\
\hline Hay-like musty & & 1.4 & 0.8 & 0.07 \\
\hline Grassy/green bean & & 0.7 & 0.3 & 0.03 \\
\hline \multirow[t]{2}{*}{ Water-like metallic } & & 0.9 & 2.0 & $<0.01$ \\
\hline & Iran & Hashemi & Khazar & \\
\hline Dairy & & 0.4 & 0.8 & 0.09 \\
\hline Sweet Taste & & 0.6 & 1.1 & 0.04 \\
\hline
\end{tabular}

higher in popcorn aroma/flavor than second best PTT1 (1.5 and 1.1, respectively; $P=0.08$ ). Quantification of 2-AP by GC-MS showed about twice as much 2-AP in KDML-105 (1,358 ppb) than in PTT-1 (637 ppb). Super Basmati, Basmati-385, and Hashemi are also aromatic. The panel found that premium Super Basmati and second best Basmati-385 had the same popcorn intensity as nonaromatic varieties (mean=0.7). GC-MS analysis, however, found $553 \mathrm{ppb}$ of 2-AP in the Super Basmati and none in the Basmati-385. The Basmati-385 was stored as rough rice for about a year prior to milling; whereas, the Super Basmati had not been stored. The 2-AP content of rough rice decreases during storage (Wongpornchai et al. 2004). Although the Super Basmati had approximately the same 2AP content as PTT1, the panelists perceived the popcorn aroma/flavor to be lower in the Super Basmati, consistent with differences in aroma/flavor between jasmine styles and basmati styles and suggesting that compounds other than 2AP contribute to their aromatic character, perhaps masking the 2-AP flavor. The popcorn aroma/flavor of Hashemi was not significantly higher than that of the non-aromatic variety $\operatorname{Khazar}$ (1.2 and 0.8 , respectively). The 2-AP content of Hashemi was 1,045 ppb, but none was detected in Khazar, further suggesting a role for volatile compounds other than 2-AP in determining popcorn aroma/flavor.

Ward's cluster analysis, using selected aromatic (Table 5) and taste/mouthfeel (Table 6) attributes, was used to determine whether the premium and second best varieties grouped into the same or different clusters. The varieties are listed in the Tables in the order they appear in the cluster analysis tree charts. The varieties did not cluster based on premium-second best classification (Tables 5 and 6). Apart from China, India, and the Philippines, varieties from each country fell in the same cluster, suggesting that flavor is specific to the country of origin. Premium Zhongzheyou1 clustered with varieties high in popcorn, corn, hay-like musty, grain/starchy, and sweet aromatic (Table 5). Its counterpart Guodao 6 clustered with ones lower in these attributes. Premium IR64 clustered with varieties high in sweet taste and low in water-like metallic, while its counterpart IRRI-132 grouped with those high in sewer animal, water-like metallic, astringent, and sour/silage and low in sweet taste (Tables 5 and 6). IRRI-132 yields very well in upland and water-scarce areas, but it has not been 
Table 5 Ward's cluster analysis using select aroma/flavor attributes to categorize varieties

\begin{tabular}{|c|c|c|c|c|c|}
\hline Variety & Country & Type & Cluster A-B $\left(r^{2}=0.58\right)$ & Cluster A1-A2 $\left(r^{2}=0.21\right)$ & Common characteristics ${ }^{\mathrm{a}}$ \\
\hline IRGA-417 (2008) & Brazil & Premium & A & A1 & \\
\hline BRS Jaçanã (2008) & Brazil & 2 nd best & A & $\mathrm{A} 1$ & \\
\hline Khazar & Iran & 2nd best & A & $\mathrm{A} 1$ & \\
\hline IR64 & Philippines & Premium & A & $\mathrm{A} 1$ & \\
\hline Pelde & Australia & Premium & A & $\mathrm{A} 1$ & \\
\hline Langi & Australia & 2nd best & A & A1 & \\
\hline Koshihikari & Japan & Premium & A & $\mathrm{A} 1$ & \\
\hline Sambha Mahsuri & India & Premium & A & $\mathrm{A} 1$ & \\
\hline Guodao 6 & China & 2nd best & A & $\mathrm{A} 1$ & \\
\hline Koshiibuki & Japan & 2nd best & A & A1 & \\
\hline Hashemi & Iran & Premium & A & $\mathrm{A} 1$ & \\
\hline Swarna & India & 2nd best & A & $\mathrm{A} 2$ & High sewer animal \\
\hline IRRI-132 & Philippines & 2 nd best & A & $\mathrm{A} 2$ & \\
\hline IRGA-417 (2009) & Brazil & Premium & $\mathrm{B}$ & & High popcorn \\
\hline PTT1 & Thailand & 2nd best & B & & High corn \\
\hline BRS Primavera & Brazil & 2 nd best & B & & High hay-like musty \\
\hline Zhongzheyou 1 & China & Premium & B & & High grain/starchy \\
\hline KDML105 & Thailand & Premium & B & & High sweet aromatic \\
\hline
\end{tabular}

The varieties listed in the table in the order they appear in the cluster analysis tree chart

${ }^{a}$ Cluster B means were significantly higher $(P<0.01)$ than cluster A means for popcorn $(1.2$ versus 0.7$)$, corn $(0.9$ versus 0.6$)$, hay-like musty $(1.3$ versus $0.9)$, grain/starchy (2.3 versus 1.9$)$, and sweet aromatic $(0.7$ versus 0.4$)$

Table 6 Ward's cluster analysis using taste and mouthfeel attributes to categorize varieties

\begin{tabular}{|c|c|c|c|c|c|}
\hline Variety & Country & Type & Cluster A-B $\left(r^{2}=0.75\right)$ & Cluster A1-A2 $\left(r^{2}=0.14\right)$ & Common characteristics ${ }^{a}$ \\
\hline IRGA-417 (2008) & Brazil & Premium & A & A1 & \\
\hline Guodao 6 & China & 2nd best & A & A1 & \\
\hline BRS Jaçanã (2008) & Brazil & 2nd best & A & $\mathrm{A} 1$ & \\
\hline IRGA-417 (2009) & Brazil & Premium & A & $\mathrm{A} 1$ & \\
\hline Koshihikari & Japan & Premium & A & $\mathrm{A} 1$ & \\
\hline Hashemi & Iran & Premium & A & A1 & \\
\hline BRS Primavera (2009) & Brazil & 2 nd best & A & $\mathrm{A} 2$ & \\
\hline Pelde & Australia & Premium & A & $\mathrm{A} 2$ & \\
\hline Khazar & Iran & 2nd best & A & $\mathrm{A} 2$ & \\
\hline PTT1 & Thailand & 2nd best & A & $\mathrm{A} 2$ & \\
\hline IR64 & Philippines & Premium & A & $\mathrm{A} 2$ & High sweet taste \\
\hline Zhongzheyou 1 & China & Premium & A & $\mathrm{A} 2$ & \\
\hline KDML105 & Thailand & Premium & A & $\mathrm{A} 2$ & \\
\hline Langi & Australia & 2nd best & A & $\mathrm{A} 2$ & \\
\hline Koshiibuki & Japan & 2nd best & A & $\mathrm{A} 2$ & \\
\hline Sambha Mahsuri & India & Premium & $\mathrm{B}$ & & High water-like metallic \\
\hline Swarna & India & 2nd best & $\mathrm{B}$ & & High astringent \\
\hline \multirow[t]{2}{*}{ IRRI-132 } & Philippines & 2 nd best & $\mathrm{B}$ & & High sour/silage \\
\hline & & & & & Low sweet taste \\
\hline
\end{tabular}

The varieties listed in the table in the order they appear in the cluster analysis tree chart

${ }^{a}$ Cluster A means were significantly higher $(P<0.01)$ than cluster B means for sweet taste $(1.1$ versus 0.5$)$ and significantly lower $(P<0.01)$ for sour/silage (0.7 versus 1.4$)$, water-like metallic (0.8 versus 1.3$)$, and astringent (1.1 versus 1.6$)$. Cluster A2 means for sweet taste (1.2 versus 0.9$)$ and water-like metallic $(0.7$ versus 0.9$)$ were significantly higher $(P<0.01)$ and lower $(P<0.02)$, respectively, than means for cluster A1 
widely accepted by consumers, even though current tools for measuring grain quality show that it is similar in quality to the highly popular IR64. If its flavor profile explains its non-adoption, quality evaluation programs need to add flavor evaluations to their repertoire. A high score for sewer animal differentiated second best Swarna from premium Sambha Mahsuri in the cluster analysis (Table 5). Analysis of variance (ANOVA), however, showed no significant differences $(P=0.16)$ in sewer animal between the two varieties. Sambha Mahsuri and Swarna clustered for the other aromatic and mouthfeel/ taste attributes, and as noted above, in a comparison of the two varieties, none of these attributes were significantly different. Thus, flavor differences do not appear to explain why Sambha Mahsuri commands much higher prices in the market than Swarna.

Comparison of texture of premium and second best varieties

Roughness was a distinguishing trait between most pairs (Table 7). The premium variety from Southeast Asia and Northern Asian countries was always less rough than the second best, but for South and Central Asia, the cooked surface of the premium variety was rougher. The cuisine of South and Central Asia is predominantly thick curries and consumers like the curry sauce to stick to the rice. A sauce is more likely to stick to a rough surface than a smooth one, which could explain the preference for surface roughness in the varieties of that region.

An association between roughness and protein content $\left(r^{2}=0.58\right)$ was observed and concurs with earlier observations (Champagne et al. 2004b, 2009). However, the present paper indicates that other factors also contribute to roughness. The $0.2 \%$ difference in protein content between Zhongzheyou 1 and Guodao 6 would be too low to result in a detectable difference in roughness by the trained panel (Champagne et al. 2009). Moreover, IRRI-132 had the highest roughness score (6.6) of all the varieties with a protein content of $8.7 \%$, and with identical protein content, IRGA-417 (2008) scored a significantly lower value for roughness, further indicating the contribution of other factors. Given that roughness was a distinguishing feature in almost all pairs, and appears to be marketspecific, it is important to understand further the biology and structures that lead to a rough surface when the grain is cooked.

Slickness was a distinguishing textural feature for five of the pairs, and in all but one case, slickness was higher in the premium variety (Table 7). In this study, slickness was negatively correlated with both protein $\left(r^{2}=0.60\right)$ and apparent amylose $\left(r^{2}=0.39\right)$ contents. These parameters could indicate differences in slickness when large differ- ences in protein and/or amylose are present. However, in the present paper, the small differences in protein and amylose contents between the premium and second best of each country are not likely to be a sufficient predictor of differences in slickness (Champagne et al. 2009).

For the varietal pairs from South and Central Asia, a number of textural attributes distinguished the premium from the second best, but common to all was springiness, which was higher in the premium variety. Springiness was not a distinguishing feature of the pairs from North and Southeast Asia, Australia, and Brazil. A weak negative correlation $\left(r^{2}=0.31\right)$ was found between springiness and amylose content, but there was no significant difference between the amylose content of each variety in each pair from South and Central Asia, suggesting that amylose is not the primary basis of springiness.

Ward's cluster analysis was used to categorize the rice based on texture characteristics described in Table 10 . Analysis using phase I texture attributes resulted in two clusters with the varieties from Iran, India, Brazil, and IRRI-132 from the Philippines comprising cluster A and cluster B composed of varieties from Japan, China, Thailand, Australia, and IR64 from the Philippines (Table 8). Cluster A contained varieties with high roughness scores. Interestingly, all varieties in cluster A, with the exception of IRRI-132, were boiled in a pan (Table 2). Excess cooking water was used for all but the Brazilian samples. This suggests that the cooking method could contribute to roughness. Cluster B was characterized by varieties that scored high for slickness, stickiness to lips, initial starchy coating, and stickiness between grains. Koshihikari and Koshiibuki had the highest scores for initial starchy coating, slickness, stickiness to lips, and stickiness between grains. All varieties in cluster B were cooked by the absorption method in rice cookers, and there is a relatively good association between the order of varieties within cluster B (Table 8) and the length of soaking time before cooking (Table 2), strengthening the need to understand the effect of cooking method on sensory properties.

\section{Conclusions}

This preliminary research has taken a snapshot approach to identifying sensory characteristics that may differentiate varieties considered by consumers to be premium and those considered to be second best in their respective countries. The major positive flavor attribute that distinguished varieties grown and traded to and within Southeast Asia was sweet taste. The major off-flavor note was water-like metallic followed by sewer/animal. The major textural attributes that distinguished cooked rice of each pair were roughness and slickness of the surface of the grain. 
Table 7 Texture attributes that differed significantly $(P<0.1)$ in intensity between premium and second best variety pairs

\begin{tabular}{|c|c|c|c|c|}
\hline Texture attribute & Country/region & Premium cultivar & Second best cultivar & Significant $P$ \\
\hline & China/N. Asia & Zhongzheyou 1 & Guodao 6 & \\
\hline Slickness & & 5.7 & 4.8 & 0.08 \\
\hline Roughness & & 4.2 & 5.1 & 0.05 \\
\hline \multirow[t]{2}{*}{ Moisture absorption } & & 5.9 & 6.8 & 0.03 \\
\hline & Japan/S.E. Asia & Koshihikari & Koshiibuki & \\
\hline \multirow[t]{2}{*}{ Slickness } & & 6.3 & 7.3 & 0.03 \\
\hline & Philippines/S.E. Asia & IR64 & IRRI-132 & \\
\hline Slickness & & 4.9 & 3.8 & 0.02 \\
\hline Roughness & & 5.4 & 6.6 & 0.03 \\
\hline \multirow[t]{2}{*}{ Stickiness to lips } & & 5.8 & 4.8 & 0.04 \\
\hline & Thailand/S.E. Asia & KDML105 & PTT1 & \\
\hline Roughness & & 4.6 & 5.4 & 0.07 \\
\hline \multirow[t]{2}{*}{ Cohesiveness } & & 5.5 & 5.0 & 0.07 \\
\hline & Australia & Pelde & Langi & \\
\hline \multirow[t]{2}{*}{ Moisture absorption } & & 5.0 & 5.9 & 0.04 \\
\hline & Brazil & BR IRGA-417 (2008) & Jaçanã (2008) & \\
\hline Initial starchy coating & & 2.5 & 1.8 & 0.01 \\
\hline Roughness & & 5.3 & 4.1 & 0.01 \\
\hline Stickiness between grains & & 4.1 & 3.1 & 0.01 \\
\hline \multirow[t]{2}{*}{ Uniformity of bite } & & 8.4 & 7.3 & $<0.01$ \\
\hline & Brazil & BR IRGA-417 (2009) & Primavera (2009) & \\
\hline Slickness & & 4.1 & 3.3 & 0.05 \\
\hline Roughness & & 4.7 & 5.7 & 0.02 \\
\hline \multirow[t]{2}{*}{ Stickiness to lips } & & 2.8 & 3.6 & 0.03 \\
\hline & Pakistan/Central Asia & Super Basmati & Basmati 385 & \\
\hline Roughness & & 5.2 & 4.3 & 0.05 \\
\hline Stickiness to lips & & 4.2 & 2.4 & $<0.01$ \\
\hline Springiness & & 2.1 & 1.4 & 0.02 \\
\hline \multirow[t]{2}{*}{ Number of chews } & & 23.4 & 18.7 & $<0.01$ \\
\hline & India/S. Asia & Sambha Mahsuri & Swarna & \\
\hline Slickness & & 3.5 & 3.0 & 0.06 \\
\hline Springiness & & 3.2 & 2.5 & 0.02 \\
\hline \multirow[t]{2}{*}{ Number of chews } & & 25.6 & 22.9 & 0.04 \\
\hline & Iran/S. Asia & Hashemi & Khazar & \\
\hline Initial starchy coating & & 1.5 & 2.2 & $<0.01$ \\
\hline Roughness & & 6.1 & 5.3 & 0.08 \\
\hline Stickiness between grains & & 3.0 & 3.9 & 0.03 \\
\hline Springiness & & 3.5 & 2.8 & 0.03 \\
\hline Hardness & & 3.9 & 3.0 & $<0.01$ \\
\hline Moisture absorption & & 6.8 & 5.9 & 0.04 \\
\hline
\end{tabular}

Springiness was important for varieties of South and Central Asia. This work has revealed a number of sensory traits of quality that are important in different markets. By understanding the structural and genetic basis of these traits, quality evaluation programs could build upon their current capacity and develop tools to enable evaluation of these traits.

\section{Experimental}

\section{Materials}

Premium and second best varieties were obtained from nine countries. Koshihikari and Koshiibuki were cultivated in the experimental field of the Niigata Prefectural Agricul- 
Table 8 Ward's cluster analysis using phase 1 texture attributes to categorize varieties

\begin{tabular}{|c|c|c|c|c|c|}
\hline Variety & Country & Type & Cluster A-B $\left(r^{2}=0.64\right)$ & Cluster B1-B2 $\left(r^{2}=0.11\right)$ & Common characteristics $^{\mathrm{a}}$ \\
\hline IRGA-417 (2008) & Brazil & Premium & A & & \\
\hline Khazar & Iran & 2nd best & A & & \\
\hline IRRI-132 & Philippines & 2nd best & A & & \\
\hline BRS Jaçanã (2008) & Brazil & 2nd best & A & & \\
\hline IRGA-417 (2009) & Brazil & Premium & A & & High Roughness \\
\hline BRS Primavera I2009) & Brazil & 2 nd best & A & & \\
\hline Sambha Mahsuri & India & Premium & A & & \\
\hline Hashemi & Iran & Premium & A & & \\
\hline Swarna & India & 2nd best & A & & \\
\hline Langi & Australia & 2nd best & B & B1 & \\
\hline Pelde & Australia & Premium & B & B1 & High Initial Starchy Coating \\
\hline KDML105 & Thailand & Premium & $\mathrm{B}$ & B1 & High Slickness \\
\hline Guodao 6 & China & 2nd best & B & B1 & High Stickiness to Lips \\
\hline PTT1 & Thailand & 2nd best & $\mathrm{B}$ & B1 & High Stickiness Between Grains \\
\hline IR64 & Philippines & Premium & $\mathrm{B}$ & B1 & \\
\hline Zhongzheyou 1 & China & Premium & $\mathrm{B}$ & B2 & High Stickiness to Lips \\
\hline Koshihikari & Japan & Premium & B & $\mathrm{B} 2$ & Higher Slickness \\
\hline Koshiibuki & Japan & 2nd best & B & B2 & $\begin{array}{l}\text { Higher Initial Starchy Coating } \\
\text { Higher Stickiness Between Grains }\end{array}$ \\
\hline
\end{tabular}

The varieties listed in the table in the order they appear in the cluster analysis tree chart

${ }^{a}$ Cluster A mean was significantly higher $(P<0.01)$ than cluster B mean for roughness (5.4 versus 4.7). Cluster B means were significantly higher $(P<0.01)$ than cluster A means for initial starchy coating (2.6 versus 2.0$)$, slickness (5.4 versus 4.0$)$, stickiness to lips (6.0 versus 3.4$)$, and stickiness between grains (4.3 versus 3.1). Cluster B2 means were significantly higher $(P<0.01)$ than cluster B1 means for initial starchy coating $(3.5$ versus 2.3$)$, slickness $(6.4$ versus 5.1), and stickiness between grains (4.8 versus 4.2). Cluster B1 mean was significantly higher $(P<0.01)$ than cluster B2 mean for roughness $(4.9$ versus 3.8) in cluster B2

tural Institute, Niigata, Japan in 2007. They were stored as rough rice for 6 months and milled identically using an experimental rice mill (Yamamoto Co., Ltd). The milled rice was stored under refrigeration for 2 months and shipped to the International Rice Research Institute (IRRI), Los Baños, Philippines. Khao Dawk Mali105 (KDML105) and Pathumthani 1 (PTT1) were grown at the Ubon Rice Research Center and Pathumthani Rice Research Center, respectively, in Thailand in 2007. The rice was stored as rough rice for 3-4 months, and both were milled identically on the same date at Ubon Rice Research Center using a mill similar to a McGill (Sintawee Co.). The milled rice was stored for 1 week at room temperature and shipped to IRRI. Zhongzheyou 1 and Guodao 6 were grown at the experimental farm of the China National Rice Research Institute, Hangzhou, China in 2007. They were stored for 5 months as rough rice and milled identically using a McGill No. 2 mill. After 15 days of storage at room temperature, they were shipped to IRRI. Super Basmati was collected from a farmer's field in the Punjab Province of Pakistan in October 2008 and milled within a week. Basmati-385 was from the 2007 crop and was obtained from the Kaku Rice Research Institute in the Punjab
Province of Pakistan. It was stored as rough rice for about a year prior to milling. Both samples were milled identically at the same time using a Satake Rice Mill No. 2. The rice was stored at room temperature for 10 days and shipped to IRRI. Hashemi and Khazar obtained from Iran were from the 2008 crop and were stored as rough rice for about 3 months prior to being commercially milled following which they were shipped within a week to IRRI. IR64, IRRI-132, Sambha Mahsuri, and Swarna were grown at IRRI in 2007. After harvest and 11 months of storage at cool temperature, the rough rice was dehulled (Otake FCY4 Dehusker), and the variety pairs were milled identically using the Grainman 65-220-60-3PH. Pelde and Langi, which are usually exported to markets in Hong Kong and Singapore, were harvested during April 2008 from plots grown at the Leeton Field Station of NSW Industry and Investment's Yanco Agricultural Institute, Yanco, NSW, Australia. They were stored for 4-5 weeks as rough rice before milling. The samples were milled identically using a "flow-through" mill (Satake Rice Whitener MCM-250) and were stored for approximately 1 month at room temperature before shipping to IRRI. BR IRGA-417 and BRS Jaçanã were harvested in 2008 at the Palmital farm of Embrapa 
Rice and Beans (Goias State, Brazil) (irrigated system) and stored for 3 months as rough rice before milling. Another sample of BR IRGA-417 (irrigated) and BRS Primavera (upland system) were harvested in 2009 at the Palmital and Capivara farms of Embrapa Rice and Beans (Goias State, Brazil), respectively, and milled without storage. All of the Brazilian varieties were milled identically using a Suzuki mill and shipped directly to the USDA ARS Southern Regional Research Center (SRRC), New Orleans, Louisiana, via expedited shipping. The other samples in the study were sealed and stored under refrigeration $\left(4^{\circ} \mathrm{C}\right)$ at IRRI, fumigated for $72 \mathrm{~h}$ with Phostoxin, and shipped to the USDA ARS SRRC via courier where the samples were refrigerated until analyzed. Samples reached the USDA 3 days after shipping from IRRI.

\section{Methods}

\section{Chemical analyses}

Apparent amylose content was determined on the samples in duplicate by the simplified iodine assay method (Juliano 1971). Protein contents $(\mathrm{N} \times 5.95)$ were determined in duplicate by the combustion method (FP-428, LECO, St. Joseph, MI). Gelatinization temperature was measured in triplicate using a differential scanning calorimeter in modulating mode (TA Instruments, DSC Q100). Flour $(4 \mathrm{mg})$ was mixed with water $(8 \mu \mathrm{L})$ in an aluminum hermetic pan which was then hermetically sealed. The temperature was raised from $35^{\circ} \mathrm{C}$ to $140^{\circ} \mathrm{C}$ at $4{ }^{\circ} \mathrm{C} / \mathrm{min}$, with modulation of $\pm 0.5^{\circ} \mathrm{C}$ every $40 \mathrm{~s}$. Thermal transitions were recorded and analyzed using Universal Analysis 2000 software. The gelatinization temperature is reported as the peak of the gelatinization endotherm.

\section{Sample preparation for sensory analyses}

The cooking protocol for each rice was typical of how the rice variety is cooked in its country of origin. Samples prepared in rice cookers: Portions $(600 \mathrm{~g})$ of milled rice were washed by covering the rice two or three times with cold water followed by straining to remove excess water. After washing, the samples were transferred to pre-weighed rice cooker insert bowls, and water was added to give the appropriate water to rice ratio, as given in Table 2 . The rice was cooked with or without prior soaking (Table 2) in a ten-cup rice cooker-steamer (randomly selected from five used) (Breville RC19XL) to completion, followed by a 10min holding period in the warm mode. Samples were taken from the rice cookers as described by (Champagne et al. 1999). Samples prepared using pan methods with excess water: Portions $(600 \mathrm{~g})$ were washed three to five times (Table 2). The rice was added to three times as much water $(w / w)$, soaked (Table 2), and boiled until the grains had no opaque center when pressed between two pieces of glass. The excess water was drained off. The drained samples from Iran (Hashemi and Khazar) were mounded on top of hot Crisco vegetable oil (2T), the pan was covered, and the rice steamed for $10 \mathrm{~min}$. Samples prepared using pan methods with complete evaporation: Portions [three cups $(\sim 600 \mathrm{~g})$ ] were washed three times and then pan-fried in Crisco vegetable oil for $5 \mathrm{~min}$. Six cups of boiling water were added, and after it reached a boil again, the rice was allowed to simmer until the water evaporated. After cooking, panprepared rice was held in the pan off the burner for $10 \mathrm{~min}$ prior to presentation. Cooking of all samples, irrespective of preparation method, was staggered, so they were analyzed at 20-min intervals by the panel.

\section{Sensory evaluation protocol}

Eight panelists trained in the principles and concepts of descriptive sensory analysis (Meilgaard et al. 2007) participated in the study. The rice flavor lexicon included 13 unique flavor attributes which were determined by smelling and evaluation in the mouth (Goodwin et al. 1996) (Table 9). The intensities were scored based on a universal scale for all foods (Meilgaard et al. 2007); the maximum rating for rice flavor attributes is generally about 5 . The lexicon for rice texture used by the panel was based on a previously developed method (Lyon et al. 1999; Goodwin et al. 1996) and is described in Table 10. The sensory texture profile used by the panelists included ten attributes that described rice texture at different phases of sensory evaluation, beginning with the feel of the rice when it was first placed in the mouth and ending with the rice being ready to swallow. Paired country samples were randomly chosen for a given session with two country sets presented at each session. Two replicates were evaluated for each variety/country, for a total of ten sessions. The details of the procedure followed for presenting samples and standard (warm-up sample of commercial long grain) to panelists at each session are as previously described (Champagne et al. 1999).

\section{Color}

Color was recorded as tristimulus $L^{*}, a^{*}$, and $b^{*}$ values using a HunterLab MiniScan XE Plus Diffuse LAV "M072096" colorimeter (Reston, VA) with a 1-in.-diameter specimen port. The standard observer was $10^{\circ}$, and the illuminant was D65 (afternoon daylight). The system was standardized using the white and black tiles provided by HunterLab for this instrument. Color was measured on the raw rice and on the cooked rice each of the two times it was prepared in triplicate. 
Table 9 Descriptive sensory analysis attributes and definitions used to evaluate cooked rice flavor (aromatics, taste, mouthfeel)

Sewer animal An immediate and distinct pungent aromatic in the flavor characterized as sulfur-like and generic animal. The animal aromatic in the flavor can sometimes be identified as "piggy."

Floral

Aromatics associated with dried flowers, such as lilac and/or lavender. This aromatic is characterized as spicy floral as in an "old fashioned sachet."

Grain starchy

A general term used to describe the aromatics in the flavor associated with grains such as corn, oats and wheat. It is an overall grainy impression characterized as sweet, brown, sometimes dusty, and sometimes generic nutty or starchy.

Hay-like musty A dry, dusty, slightly brown aroma/flavor with a possible trace of musty.

Popcorn

Corn

A dry, dusty, slightly toasted and slightly sweet aromatic in the flavor that can be specifically identified as popcorn.

The sweet aromatics of the combination of corn kernels, corn milk, and corn germ found in canned yellow creamed-style corn.

Alfalfa/grassy/green A dried, green, slightly earthy, slightly sweet aroma/flavor including grassy and fresh green bean aroma/flavor.

beans

Dairy

Sweet aromatic

A general term associated with the aromatics of pasteurized cow's milk. Most apparent just before swallowing.

Water-like metallic

A sweet impression such as cotton candy, caramel, or sweet fruity that may appear in the aroma and or aromatics.

Aromatics and mouthfeel of the minerals and metals commonly associated with tap water.

This excludes any chlorine aromatics that may be perceived.

Sweet taste

Basic sweet taste associated with sugar

Sour/silage

A sour fermented vegetation aroma/flavor, not decaying vegetation.

Astringent

The chemical feeling factor on the tongue, described as puckering/dry and associated with tannins or aluminum.

\section{2-Acetyl-1-pyrroline analysis}

The method of Bergman et al. (2000) was employed for the quantification of 2-acetyl-1-pyrroline (2-AP). In brief, $0.3 \mathrm{~g}$ of rice flour was placed in a 2-ml vial. A solution of $0.5 \mathrm{ml}$ of $\mathrm{MeCl} 2$ containing 2,4,6-trimethylpyridine (TMP) (Sigma-Aldrich, St Louis, MO) at a concentration of $485 \mathrm{ppb}$ was added to the vial and capped with a steel cap. The vials were heated at $85^{\circ} \mathrm{C}$ for $2.5 \mathrm{~h}$ to ensure complete gelatinization of the rice samples. An Agilent 7890 GC (Agilent Technologies, Folsom, CA) equipped with a $30-\mathrm{m} \times 0.25$-mm DB-WAX capillary column $(\mathrm{J} \& \mathrm{~W}$ Scientific, St. Joseph, MO) was used for analysis. Aliquots of $2 \mu \mathrm{l}$ were injected into an injection port operated in splitless mode at $155^{\circ} \mathrm{C}$. The oven was initially held for $1 \mathrm{~min}$ at $40^{\circ} \mathrm{C}$ then increased at a rate of $9^{\circ} \mathrm{C} / \mathrm{min}$ to $120^{\circ} \mathrm{C}$ and then at

Table 10 Sensory descriptive texture attributes and their definitions used to evaluate cooked rice texture

\begin{tabular}{ll}
\hline Phases/attributes & Definition \\
\hline Phase I & Place 6-7 grains of rice in mouth behind front teeth. Press tongue over surface and evaluate. \\
Initial starchy coating & Amount of paste-like thickness perceived on the product before mixing with saliva (3 passes). \\
Slickness & Maximum ease of passing tongue over the rice surface when saliva starts to mix with sample. \\
Roughness & Amount of irregularities in the surface of the product. \\
Stickiness to lips & Degree to which kernels adhere to lips. \\
Stickiness between grains & Degree to which the kernels adhere to each other. \\
Phase II & Place $1 / 2$ teaspoon of rice in mouth. Evaluate before or at first bite. \\
Springiness & Degree grains return to original shape after partial compression. \\
Cohesiveness & Degree to which the grains deform rather than crumble, crack, or break when biting with molars. \\
Hardness & Force required to bite through the sample with the molars. \\
Phase III & Evaluate during chew. \\
Cohesiveness of mass & Maximum degree to which the sample holds together in a mass while chewing. \\
Chewiness & Amount of work to chew the sample. \\
Uniformity of bite & Evenness of force throughout bites to chew. \\
Moisture absorption & Amount of saliva absorbed by sample during chewing. \\
Phase IV & Evaluate after swallow. \\
Residual loose particles & Amount of loose particles in mouth. \\
Toothpack & Amount of product adhering in/on the teeth. \\
\hline
\end{tabular}


a rate of $25^{\circ} \mathrm{C} / \mathrm{min}$ to $250^{\circ} \mathrm{C}$ and held for $5 \mathrm{~min}$. Samples were run in triplicate, and concentration of 2-AP was calculated on the relative peak areas of the 2-AP peak and the TMP peak.

\section{Statistical analyses}

Analysis of variance (ANOVA) was used to compare the varieties for all countries combined and within each country for flavor and texture attributes. Ward's cluster analysis was also performed using standardized data to determine if rice varieties could be grouped based on similarities in flavor and texture characteristics. Three sets of variables were used in the cluster analyses: (1) aromas/flavors (sewer animal, grain/starchy, hay-like musty, popcorn, corn, and sweet aromatic), (2) taste (sour/silage and sweet taste) and mouthfeel (astringent and water-like metallic) attributes, and (3) texture at phase I of sensory evaluation (Table 10). Cluster means were compared using Tukey-Kramer honestly significant difference tests. The combined data comparisons were performed both with and without the Super BasmatiBasmati-385 pair because the samples were stored for different lengths of time prior to milling. Storage time of rough rice has been shown to affect the flavor and texture of milled rice (Meullenet et al. 2000), so the Super BasmatiBasmati-385 pair was excluded from the cluster analysis. All statistical analyses were performed using SAS $^{\circledR}$ software, version 9.2; Enterprise Guide, version 4.1; and $\mathrm{JMP}^{\circledR}$ software, version 8.0.1 (SAS Institute Inc., Cary, NC). Results were considered significant at the 0.10 level for the sensory analyses; other data were reported significant at $P<0.05$.

Acknowledgments The authors thank Dr. Kazuhiko Ishizaki of the Niigata Prefectural Agricultural Research Institute for the kind gift of the Koshihikari and Koshiibuki rice, Dr. Rosa Cuevas from the IRRI for carrying out the DSC work, Dr. Ming Chen at the USDA Rice Quality Laboratory (Beaumont, TX) for the amylose analyses, and Ms. Kim Daigle at the USDA ARS Southern Regional Research Center for the protein analyses.

\section{References}

Bergman CJ, Delgado JT, Bryant R, Grimm C, Cadwallader KR, Webb BD. Rapid gas chromatographic technique for quantifying 2-acetyl-1-pyrroline and hexanal in rice (Oryza sativa, L.). Cereal Chem. 2000;77:454-8.

Buttery R, Ling LC, Juliano BO, Turnbaugh JG. Cooked rice aroma and 2-acetyl-1-pyrroline. J Agric Food Chem. 1983;31:823-6.
Champagne ET, Bett KL, Vinyard BT, Webb BD, McClung AM, Barton FE, et al. Effects of drying conditions, final moisture content, and degree of milling on rice flavour. Cereal Chem. 1997;74:566-70.

Champagne ET, Bett KL, Vinyard BT, McClung AM, Barton FE, Moldenhauer K, et al. Correlation between cooked rice texture and rapid visco analyser measurements. Cereal Chem. 1999;76:764-71.

Champagne ET, Thompson JF, Bett-Garber KL, Mutters R, Miller JA, Tan E. Impact of storage of freshly harvested paddy rice on milled rice flavor. Cereal Chem. 2004a;81:444-9.

Champagne ET, Bett-Garber KL, McClung AM, Bergman C. Sensory characteristics of diverse rice varieties as influenced by genetic and environmental factors. Cereal Chem. 2004b;81:237-43.

Champagne ET, Bett-Garber KL, Grimm CC, McClung AM. Effects of organic fertility management on physicochemical properties and sensory quality of diverse rice varieties. Cereal Chem. 2007;84:320-7.

Champagne ET, Bett-Garber KL, Thomson JL, Fitzgerald MA. Unraveling the impact of nitrogen nutrition on cooked rice flavor and texture. Cereal Chem. 2009;86:274-80.

Fitzgerald MA, McCouch SR, Hall RD. Not just a grain of rice: the quest for quality. Trends Plant Sci. 2009;14:133-9.

Goodwin HL Jr, Rister ME, Branson RE, Stansel JW, Webb BD, Ward $\mathrm{JB}$, et al. Market potential for domestic rice varieties among Asian-Americans. TAMRC Consumer Product Market Research CP-1-92T. College Station, TX: Texas A \& M; 1992.

Goodwin HL, Koop LA, Rister ME, Miller RK, Maca JV, Chambers E, et al. Developing a common language for the U.S. rice industry: linkages among breeders, producers, processors, and consumers. TAMRC Report. College Station: Texas A \& M University; 1996.

Juliano BO. A simplified assay for milled-rice amylose. Cereal Sci Today. 1971;16:334-60.

Lyon BG, Champagne ET, Vinyard BT, Windham WR, Barton FE, Webb BD, et al. Effects of degree of milling, drying conditions, and final moisture content on sensory texture of cooked rice. Cereal Chem. 1999;76:56-62.

Meilgaard M, Civille GV, Carr BT. Sensory evaluation techniques. Boca Raton: CRC Press; 2007.

Meullenet JF, Marks BP, Griffin K, Daniels MJ. Effects of rough rice drying and storage conditions on sensory profiles of cooked rice. Cereal Chem. 1999;76:438-86.

Meullenet J-F, Marks BP, Hankins J-A, Griffin VK, Daniels MJ. Sensory quality of cooked long-grain rice as affected by rough rice moisture content, storage temperature, and storage duration. Cereal Chem. 2000;77:259-63.

Schieberle P. Primary odorants of popcorn. J Agric Food Chem. 1991;39:1141-4.

Suwansri S, Meullenet J-F, Hankins JA, Griffin K. Preference mapping of domestic/imported Jasmine rice for U.S.-Asian consumers. J Food Sci. 2002;67:2420-31.

Wongpornchai S, Dumri K, Jongkaewwattana S, Siri B. Effects of drying methods and storage time on the aroma and milling quality of rice (Oryza sativa, L.) cv Khao Dawk Mali 105. Food Chem. 2004;87:407-14. 